\title{
KOQИPOBAHИE $\mathrm{n}$ BbIБOP ПEPBOHACAПЫHOЙ ПPИЧИHЫ CMEPTИ ПРИ TРАВМАX И ОТРАВПEHНИЯ B COOTBETCTBИИ C OБ̈НОВЕEHИЯMИ B03
}

к.м.н. Д.Ш. Вайсман

ФГБУ «Центральный научно-исследовательский институт организации и информатизации здравоохранения» Минздрава России (дир. - д.м.н., проф., акад. РАН, В.И. Стародубов), Москва

Аннотация: Статья посвящена новым правилам кодирования и выбора первоначальной причины смерти при травмах и отравлениях в соответствии с официальными обновлениями ВО3 1996-2012г.г. Обращено внимание на получение достоверной статистической информации о смерти, необходимой для детального анализа, являющегося основой для разработки мероприятий, направленных на снижение показателей смертности.

Ключевые слова: статистика смертности, МКБ-10, кодирование, причины смерти, медицинское свидетельство о смерти, достоверность статистики смертности

\section{CODING AND SELECTION OF THE UNDERLYNG CAUSE OF DEATH FOR INJURIES AND POISONINGS IN ACCORDANCE WITIH ICD-10 UPDATES}

D.Sh. Vaisman

Abstract: The article is devoted to new coding rules and selection of the underlying cause of death for injuries and poisoning according to official WHO updates 1996-2012. The attention to obtaining reliable statistical information about the death for the detailed analysis that is a basis for development of the arrangements directed to decline avoidable mortality rates is paid.

Keywords: mortality statistics, ICD-10, coding, causes of death, medical certificate of death, reliability of mortality statistics

Одним из приоритетов нашего государства является демографическая политика, ориентированная, прежде всего, на снижение смертности и увеличение продолжительности жизни.

Важным условием является получение достоверной статистической информации о причинах смерти, позволяющей правильно планировать мероприятия, направленные на снижение смертности.

Для того чтобы получать достоверные данные о смертности необходимо соблюдать единые правила учета, сбора, кодирования и обработки медико-статистической информации.

Основой достоверной статистической информации является Международная статистическая классификация болезней и проблем, связанных со здоровьем, 10 пересмотра (МКБ-10), введенная во всех медицинских организациях Российской Федерации с 01.01.1999 года (приказ Минздрава России от 27.05.1997 г. № 170) [2].

«Классификацию болезней можно определить как систему рубрик, в которые конкретные нозологические единицы включены в соответствии с принятыми критериями. Целью международной классификации болезней является создание условий для систематизированной регистрации, анализа, сравнения и интерпретации данных о заболеваемости и смертности, полученных в разных странах или регионах и в разное время» (МКБ-10, том 2, стр. 2) [2].

Всемирная организация здравоохранения (ВО3) определяет МКБ-10, как мировой стандарт медицинской информации для статистики смертности и заболеваемости. С помощью МКБ-10 более чем 100 стран ис- пользуют систему отчетов в ВОЗ данных о смертности, основного показателя состояния здоровья.

Сердцевиной МКБ-10 является трехзначный код, являющийся обязательным уровнем кодирования данных о смертности для предоставления в ВО3, а также для проведения международных сравнений.

В отличие от предыдущих пересмотров, в МКБ-10 вместо цифрового применен буквенно-цифровой код с буквой английского алфавита в качестве первого знака и цифрой во втором, третьем и четвертом знаке кода. Четвертый знак следует за десятичной точкой и является обязательным на уровне территории.

Одним из наиболее важных понятий в МКБ-10 является система двойного кодирования $[1,2,5]$. К ней относится:

- система кодирования крестик $(\dagger)$ и звездочка $(*)$; при этом главным является код основного состояния (заболевание, травма, отравление), помеченный крестиком (†); а дополнительный код, помеченный звездочкой $(\star)$, в официальной статистике не применяется;

- при травмах и отравлениях применяют двойное кодирование: один код из класса XIX - код характера травмы или отравления, второй - код внешней причины (класс XX). В мировой статистике код внешней причины считается основным, а код характера травмы или отравления - дополнительным. В Российской Федерации при травмах и отравлениях используют оба кода как равнозначные.

Для того чтобы правильно закодировать, или присвоить код той или иной формулировке диагноза, существует специальный алгоритм кодирования (МКБ-10, том 2, стр. 31-32) [2]. 
Диагноз в случае смерти от различных причин должен быть записан в первичной медицинской документации в соответствии с установленными требованиями [5].

При формулировании диагноза при травмах и отравлениях его необходимо разбивать на разделы. щие:

Общепризнанными разделами считаются следую-

1. основное состояние (травма или отравление);

2. осложнения основного состояния, которые желательно

сгруппировать по степени тяжести;

3. внешняя причина травмы или отравления;

4. фоновые и конкурирующие болезни;

5. сопутствующие травмы и заболевания.

В соответствии с МКБ-10 «основным» считается то состояние (травма, отравление), которое само по себе или через свои осложнения явилось поводом для обращения за медицинской помощью, стало причиной госпитализации и (или) смерти. При наличии более одной травмы, «основной» считают ту, на долю которой пришлась наибольшая часть использованных ресурсов $[1,2]$.

Статистика причин смерти основана на концепции «первоначальной причины смерти», которая была одобрена на Международной конференции по Шестому пересмотру в Париже в 1948 году.

Первоначальная причина смерти - это:

- болезнь или травма, вызвавшая цепь событий, непосредственно приведших к смерти

- обстоятельства несчастного случая или акта насилия, которые вызвали смертельную травму

Это определение продиктовано тем, что, выстроив цепь событий, приведших к смерти, можно в ряде случаев повлиять на нее, с целью предотвращения смерти $[1,2]$.

Статистика смертности формируется на основании учетной формы № 106/y-08 «Медицинское свидетельство о смерти» (Свидетельство), утвержденной приказом Минздравсоцразвития России от 26.12.2008 г. № 782н «Об утверждении и порядке ведения медицинской документации, удостоверяющей случаи рождения и смерти».

Письмом Минздравсоцразвития России от 19.01.2009 г. № 14-6/10/2-178 во все субъекты Российской Федерации были направлены методические рекомендации по порядку выдачи и заполнения медицинских свидетельств о рождении и смерти.

Заполнение пункта 19 Свидетельства производится следующим образом. В каждом подпункте части I указывается только одна причина смерти, при этом может быть заполнена строка подпункта а), строки подпунктов а) и б) или строки подпунктов а), б) и в). Для заполнения первых трех строк части I как правило используются коды из классов I-XIX МКБ-10.

Строка подпункта г) части I заполняется во всех случаях, когда причиной смерти являются травмы; на этой строке записывают формулировку внешней причины с указанием места происшествия, приблизительный период времени между началом патологического процесса и смертью и код внешней причины из класса $\mathrm{XX}$ «Внешние причины заболеваемости и смертности» МКБ-10.

Заполнение первых трех строк части I пункта 19 Свидетельства производится в обратной последовательности к основному состоянию с осложнениями: формулировка основной травмы заносится, как правило, на строку подпункта в). Затем выбирается 1-2 смер- тельные осложнения, из которых составляют «логическую последовательность» и записывают их на строках подпунктов а) и б). При этом состояние, записанное строкой ниже, должно являться причиной возникновения состояния, записанного строкой выше.

В части I пункта 19 может быть записана только одна нозологическая единица - состояние, обозначенное в МКБ-10 самостоятельной рубрикой или подрубрикой.

Часть II пункта 19 включает прочие причины смерти - это те прочие важные травмы и заболевания (фоновые, конкурирующие и сопутствующие), которые не были связаны с первоначальной причиной смерти, но способствовали наступлению смерти. При этом производится отбор только тех состояний, которые оказали свое влияние на данную смерть (утяжелили основное состояние и ускорили наступление смерти). В данной части также указывают факт употребления алкоголя, наркотических средств, психотропных и других токсических веществ, содержание их в крови, а также произведенные операции или другие медицинские вмешательства (название, дата), которые, по мнению врача, заполняющего Свидетельство, имели отношение к смерти.

Не следует включать в Свидетельство в качестве причин смерти симптомы и состояния, сопровождающие механизм смерти, например, такие, как сердечная или дыхательная недостаточность, которые встречаются у всех умерших $[1,2,4,5]$.

После заполнения всех необходимых строк пункта 19 Свидетельства необходимо присвоить код всем записанным состояниям и выбрать первоначальную причину смерти в строгом соответствии с правилами МКБ-10 с учетом обновлений ВОЗ 1996-2012 г.г. [2, 3].

Для формирования статистики заболеваемости и смертности в МКБ-10 имеются 2 способа кодирования травм и отравлений. Первый способ заключается в использовании кодов множественных травм (Т00-Т06). При втором способе в качестве первоначальной причины смерти из 2-3 наиболее тяжелых травм выбирают только одну, основную, а 1-2 другие записывают в части II Свидетельства в качестве сопутствующих состояний $[5,6]$.

В статистике смертности в Российской Федерации используется второй способ, так как он дает возможность формировать подробную статистику, позволяющую органам управления здравоохранением по данным анализа оперативно вносить изменения в организацию оказания медицинской помощи при травмах и отравлениях (реструктуризация штатов и коечного фонда).

В соответствие с правилами МКБ-10 формулировка основной травмы или отравления должна быть записана в части I Свидетельства с соблюдением логической последовательности. При построении логической последовательности используются смертельные осложнения основной травмы. При правильном заполнении Свидетельства первоначальная причина смерти определяется по «Общему принципу» и должна располагаться на нижней заполненной строке части I.

Однако обновлениями ВОЗ с января 2013 года первоначальная причина смерти по характеру травмы определяется не по «Общему принципу», а по ранговой таблице [6]. При этом отбираются 2-3 наиболее тяжелые травмы или отравления, каждой травме присваивается код по МКБ-10, по ранговой таблице определяют, какой ранг соответствует каждому коду. Травма с кодом, имеющим наименьший ранг, выбирается в качестве первоначальной причины смерти. 
При определении первоначальной причины смерти при отравлениях используются другие правила, также установленные обновлениями ВОЗ.

В случае смерти пациента от отравлений препаратами, медикаментами и биологическими веществами придерживаются следующих правил.

1. Если записано только одно вещество, вызвавшее смерть, кодируют отравление этим веществом по характеру и внешней причине.

2. Если имеется комбинация лекарственных средств, классифицированных в одной рубрике, выбор и кодирование первоначальной причины смерти производится следующим образом.

Если классификация предусматривает определенную рубрику для комбинации препаратов, например, смешанные противоэпилептические средства (Т42.5), кодируют эту рубрику.

Если нет соответствующей доступной комбинации в рубрике, выбирают код первоначальной причины смерти по характеру отравления и кодируют в следующем порядке очередности:

Группа 1. Опиаты (Т40.0-T40.2)

Если комбинации включенных опиатов классифицируются в более чем одной четырехзначной подрубрике в Т40.0-Т40.2: кодируют Т40.2

Группа 2. Кокаин (Т40.5)

Группа 3. Психостимуляторы, характеризующиеся возможностью пристрастия к ним (Т43.6)

Включен: амфетамин и его производные

Группа 4. Синтетические наркотики и другие и неуточненные наркотики (Т40.3-Т40.4, Т40.6)

Комбинации, включающие синтетические наркотики, классифицированные в более чем одной четырехзначной подрубрике в Т40.3-T40.4: кодируют Т40.4

Комбинации, включающие синтетические наркотики, классифици-рованные в более чем одной четырехзначной подрубрике в Т40.3-Т40.4 с другими и неуточненными наркотиками, классифицированными в Т40.6: кодируют Т40.6

Группа 5. Антидепрессанты (Т43.0-Т43.2)

Комбинации, включающие антидепрессанты, классифицированные в более чем одной четырехзначной подрубрике в Т43.0-Т43.2: кодируют Т43.2

Группа 6. Ненаркотические анальгетики (Т39. -)

Комбинации, включающие ненаркотические анальгетики, классифи-цированные в более чем одной четырехзначной подрубрике в Т39.0-Т39.4: кодируют Т39.8.

Группа 7. Лекарственные средства и вещества, не перечисленные выше.

Если в свидетельство о смерти записывается более чем одно такое лекарственное средство, кодируют первое записанное средство.

Если имеется более чем одно лекарственное средство в одной приоритетной группе, кодируют первое записанное средство [7].

3. В случае смерти пациента от отравлений лекарственными средствами, классифицированными в разных рубриках, поступают следующим образом:

3.1. Если один из компонентов комбинации определен как самое важное вещество, повлекшее смерть, кодируют этот компонент по характеру отравления.

Внешние причины определяются в зависимости от обстоятельств: случайные отравления, самоотравления, нападения с применением лекарственных средств и отравления с неопределенными намерениями.

3.2. Если ни один из компонентов не указывается как самое важное вещество, повлекшее смерть, уточнение не может быть получено от лица, заполнившего Свидетельство, и, если имеется более чем одно лекарственное средство из одной приоритетной группы, кодируют первое записанное средство [7].

3.3. Когда состояния из рубрик F10-F19 записаны с тем же отравлением, или передозировкой (Т40-Т65), внешнюю причину кодируют в соответствии с обстоятельствами, записанными в Свидетельстве:

- X40-Х49 Случайное отравление и воздействие ядовитыми веществами, кодируют рубриками X40-X49

- X60-Х69 Преднамеренное самоотравление и воздействие вредных веществ, кодируют рубриками X60-X69

- Х85-Х90 Нападение с применением вредных веществ, кодируют рубриками Х85-Х90

- Ү10-Ү19 Отравление и воздействие наркотиков, химических и вредных веществ с неопределенными намерениями, кодируют рубриками Ү10-Ү19

Психические и поведенческие расстройства, связанные с употреблением психоактивных веществ (F10-F19), записанные с упоминанием об острой интоксикации (Четырехзначная подрубрика .0), кодируют рубриками $\mathrm{X} 40-\mathrm{X} 49, \mathrm{X} 60-\mathrm{X} 69, \mathrm{X} 85-\mathrm{X} 90$ или Y10-Y19 в зависимости от обстоятельств отравления.

3.4. Если в Свидетельстве записано отравление алкоголем и другими лекарственными средствами, то по характеру отравление кодируют рубрикой «Отравление другими лекарственными средствами» (Т50.9), а по внешней причине - «Отравление и воздействие другими и неуточненными лекарственными средствами, медикаментами и биологическими субстанциями» (X44) [7].

В случае смерти пациента, когда сочетаются заболевания, вызываемые употреблением алкоголя, отравления алкоголем или психические и поведенческие расстройства, придерживаются следующих правил.

Если в качестве «основного состояния» определено одно из заболеваний печени (К71-К76) при наличии признаков отравления алкоголем (Т51.-), это заболевание печени следует записывать в части I Свидетельства с обязательным указанием логической последовательности. Отравление алкоголем (Т51.-) записывают в части II Свидетельства, как состояние, способствовавшее смерти. Первоначальную причину смерти в этих случаях выбирают в соответствии с Таблицей 1. Здесь должна быть также записана внешняя причина и ее код.

Перечень кодов XIX класса и соответствующих им кодов XX класса МКБ-10, применяемых для кодирования при отравлениях некоторыми лекарственными средствами и химическими веществами, приведен в МКБ-10 (том 3, стр. 765-917).

Правила МКБ-10 многочисленны и сложны в применении, поэтому во многих странах используются автоматизированные системы, позволяющие освободить врача от несвойственных функций - кодирования и выбора первоначальной причины смерти.

От соблюдения правил кодирования состояний, связанных с употреблением психоактивных веществ и выбора первоначальной причины смерти в соответствии с МКБ-10 с обновлениями ВОЗ, зависит формирование достоверной международно сопоставимой медицинской статистики, пригодной для анализа по первоначальной и множественным причинам смерти, что позволит разрабатывать конкретные мероприятия, направленные на снижение показателей смертности. 
Выбор первоначальной причины смерти при некоторых заболеваниях печени

Таблица

\begin{tabular}{|c|c|c|}
\hline $\begin{array}{l}\text { Код основного } \\
\text { состояния }\end{array}$ & $\begin{array}{c}\text { С упоминанием о } \\
\text { (записано в части II) } \\
\text { Свидетельства: }\end{array}$ & Код ППС \\
\hline К71.0 & T51.- & К70.9 \\
\hline К71.1 & T51.- & К70.4 \\
\hline К71.2 & T51.- & К70.1 \\
\hline K71.3 & T51.- & К70.1 \\
\hline К71.4 & T51.- & К70.1 \\
\hline К71.5 & T51.- & К70.1 \\
\hline К71.6 & T51.- & К70.1 \\
\hline К71.7 & T51. - & К70.2 \\
\hline К71.8 & T51.- & К70.0 \\
\hline К71.9 & T51.- & К70.9 \\
\hline K72.- & T51.- & К70.4 \\
\hline K72.- & F10. & K70.4 \\
\hline K73.- & T51.- & К70.1 \\
\hline K73.- & F10.- & К70.1 \\
\hline К74.0-2 & T51.- & К70.2 \\
\hline К74.0-2 & F10.- & К70.2 \\
\hline К74.6 & T51.- & К70.3 \\
\hline К74.6 & F10. & К70.3 \\
\hline К75.9 & T51.- & К70.1 \\
\hline К75.9 & F10.- & К70.1 \\
\hline К76.0 & T51.- & К70.0 \\
\hline К76.0 & F10.- & К70.0 \\
\hline К76.9 & T51.- & К70.9 \\
\hline К76.9 & F10.- & К70.9 \\
\hline
\end{tabular}

\section{ЛИТЕРАТУРА}

1. Вайсман, Д.Ш. Руководство по использованию Международной классификации болезней в практике врача: в 2-х томах, том 1-й. /Вайсман Д.Ш. //М.: РИО ЦНИИОИЗ, - 2013 г. - С. 168

2. Международная статистическая классификация болезней и проблем, связанных со здоровьем; 10-й пересмотр: В 3 т./ ВОЗ. - Женева, 1995-1998. - Т.1 - 3.

3. Официальные обновления BO3 1996-2012 г.г. URL: http://www.who.int/classifications/icd/icd10updates/en/ (Дата обращения: 05.01.2015)

4. Письмо Министерства здравоохранения и социального развития Российской Федерации от 19.01.2009 г. № 14-6/10/2-178 «О порядке выдачи и заполнения медицинских свидетельств о рождении и смерти».
5. Письмо Министерства здравоохранения и социального развития Российской Федерации от 30.09.2011 г. № 14-9/10/2-9696 «Об особенностях кодирования травм при дорожно-транспортных происшествиях в соответствии с МКБ-10».

6. Порядок оформления «Медицинских свидетельств о смерти» в случаях смерти от транспортных несчастных случаев, включая ДТП, в соответствии с МКБ-10. Методические рекомендации /Вайсман Д.Ш., Леонов С.А. Ковалев А.В. //М.: ЦНИИОИЗ, 2013. - С. 20

7. Порядок статистического учета и кодирования состояний, связанных с употреблением психоактивных веществ, в соответствии с МКБ-10. Методические рекомендации /Вайсман Д.Ш., Леонов С.А. //М.: ЦНИИОИЗ, 2013. - С. 32

\section{Для корреспонденции}

ВАЙСМАН Давид Шуневич - ФГБУ «Центральный научно-исследовательский институт организации и информации здравоохранения» Министерства здравоохранения Российской федерации. 127254, Москва, ул. Добролюбова, д. 11・E-mail: dv55@mail.ru 